\title{
1 Functional analysis of the archaea, bacteria, and viruses from a halite endolithic microbial community
}

4 Alexander Crits-Christoph ${ }^{1}$, Diego R. Gelsinger ${ }^{1}$, Bing $\mathrm{Ma}^{2}$, Jacek Wierzchos ${ }^{3}$, Jacques

5 Ravel $^{2}$, Alfonso Davila ${ }^{4}$, M. Cristina Casero ${ }^{3}$, and Jocelyne DiRuggiero ${ }^{1 \S}$

$6{ }^{1}$ Biology Department, The Johns Hopkins University, Baltimore, MD, USA; ${ }^{2}$ Institute for

7 Genome Sciences, University of Maryland School of Medicine, Baltimore, MD, USA;

$8{ }^{3}$ Museo Nacional de Ciencias Naturales, MNCN - CSIC, Madrid, Spain; ${ }^{4}$ Carl Sagan

9 Center, SETI Institute, Mountain View, CA, USA

11 Running Title: halite metagenome

12 Keywords: halite, endoliths, cyanobacteria, archaea, viruses, extreme environment,

13 Atacama Desert, metagenomics

15 `Corresponding author:

16 Jocelyne DiRuggiero

17 Johns Hopkins University

18 Biology Department

193400 N. Charles Street, Mudd Hall

20 Baltimore MD 21218, USA

21 Phone: 410-516-8498

22 Fax: 410-516-5213

23 Email: jdiruggiero@jhu.edu

26 The authors declare that there are no competing financial interests in relation to the

27 work described here. 


\section{Abstract}

30 Halite endoliths in the Atacama Desert represent one of the most extreme microbial

31 ecosystems on Earth. Here we sequenced and characterized a shotgun metagenome from

32 halite nodules collected in Salar Grande, Chile. The community is dominated by archaea

33 and functional analysis attributed most of the autotrophic $\mathrm{CO}_{2}$ fixation to a unique

34 cyanobacterium. The assembled 1.1 Mbp genome of a novel nanohaloarchaeon,

35 Candidatus Nanopetramus SG9, revealed a photoheterotrophic life style and a low

36 median isoelectric point $(\mathrm{pI})$ for all predicted proteins, suggesting a "salt-in" strategy for

37 osmotic balance. Predicted proteins of the algae identified in the community also had pI

38 distributions similar to "salt-in" strategists. The Nanopetramus genome contained a

39 unique CRISPR/Cas system with a spacer that matched a partial viral genome from the

40 metagenome. A combination of reference-independent methods identified over 30

41 complete or near complete viral or proviral genomes with diverse genome structure,

42 genome size, gene content, and hosts. Putative hosts included Halobacteriaceae,

43 Nanohaloarchaea, and Cyanobacteria. Despite the dependence of the halite community

44 on deliquescence for liquid water availability, this study exposed an ecosystem spanning

45 three phylogenetic domains, containing a large diversity of viruses, and a predominant

46 "salt-in" strategy to balance the high osmotic pressure of the environment. 


\section{Introduction}

49 In the most arid deserts on Earth, microorganisms find refuge inside rock substrates as a

50 survival strategy (Pointing and Belnap, 2012, Wierzchos et al., 2012b). The rock

51 environment provides physical stability, protection from incident UV and excessive shifts

52 in temperature, and enhances moisture availability (Chan et al., 2012, Walker and Pace,

53 2007). The colonized substrates are translucent, allowing primary production to occur via

54 photosynthesis (Walker and Pace, 2007, Wierzchos et al., 2012b). These endolithic

55 communities are typically composed of cyanobacteria associated with diverse

56 heterotrophic bacteria and/or archaea, and sometimes eukaryotes (Chan et al., 2013,

57 Robinson et al., 2015, Wierzchos et al., 2012b). The diversity of rock habitats colonized

58 by microorganisms has shown that life has found innovative ways to adapt to the extreme

59 conditions of hyper-arid deserts (Friedmann 1982, DiRuggiero et al., 2013, Pointing et al.,

60 2009, Wei et al., 2015, Wierzchos et al., 2012b). This is in stark contrast to soil, where

61 microorganisms under extreme water stress and restricted access to nutrient must undergo

62 long periods of stasis (Crits-Christoph et al., 2013).

63 The Atacama Desert in Northern Chile is one of the oldest and driest deserts on Earth

64 (Clarke 2006). In the hyper-arid zone of the desert, with decades between rainfall events

65 and extremely low air relative humidity $(\mathrm{RH})\left(\right.$ mean $\mathrm{yr}^{-1}$ values $<35 \%$ ), deliquescence of

66 ancient halite crusts of evaporitic origin was shown to provide sufficient moisture to

67 sustain microbial communities (Davila et al., 2008, de los Rios et al., 2010, Robinson et

68 al., 2015, Wierzchos et al., 2012a). Within the halite nodules, capillary condensation of

69 water vapor at air RH as low as $50-55 \%$, due to the presence of pores smaller than 100

$70 \mathrm{~nm}$ surrounding large $\mathrm{NaCl}$ crystals inside the nodules, was reported as a potential source 
71 of water for microorganisms (Davila et al., 2008, Wierzchos et al., 2012a). Under these

72 conditions, the halite nodule interior in the Yungay area of the hyper-arid core remained

73 wet for 5,362 hours $\mathrm{yr}^{-1}$ (Wierzchos et al., 2012a). In contrast, in Salar Grande, located in

74 the southwest area of the Tarapacá Region, coastal fogs are frequent (Cereceda et al.,

75 2008a, Cereceda et al., 2008b) leading to constant moisture inside the nodules (Robinson

76 et al., 2015).

77 High-throughput culture-independent methods based on 16S rRNA gene sequencing have

78 shown that the Atacama halite communities were dominated by archaea from the

79 Halobacteriaceae family. The communities also contained a unique cyanobacterium

80 related to Halothece species and diverse heterotrophic bacteria (de los Rios et al., 2010,

81 Robinson et al., 2015). Halite communities exposed to costal fogs were more diverse and

82 harbored a novel type of algae that was not found in the Yungay nodules, suggesting that

83 the environmental conditions in this habitat might be too extreme for eukaryotic

84 photosynthetic life (Robinson et al., 2015).

85 Assimilation of atmospheric radiocarbon into the halite microbial community biomass

86 showed that carbon cycling inside the halite nodules was ongoing, with carbon turnover

87 times of less then a decade in Salar Grande (Ziolkowski et al., 2013). Measurements of

88 chlorophyll fluorescence using Pulse Amplitude Modulated (PAM) fluorometry recently

89 demonstrated in situ active metabolism in halite endolithic communities (Davila et al.,

90 2015). Photosynthetic activity was tightly linked to moisture availability and solar

91 insolation and was sustained for days after a wetting event (Davila et al., 2015).

92 Radiolabelled experiments showed that the halite communities fixed $\mathrm{CO}_{2}$ via 
93 photosynthesis and further evidence of metabolic activity was supported by oxygen

94 production and respiration (Davila et al., 2015).

95 To further characterize halite endoliths, we sequenced the pooled metagenome of a

96 microbial community associated with halite nodules. We found novel microorganisms,

97 community members from the three domains of life, and a large diversity of viruses. The

98 functional annotation of the metagenome revealed communities highly specialized to the

99 extreme salinity of the environment.

100

\section{Materials and methods}

\section{Sampling, DNA extraction, and sequencing}

103 The colonization zone from 5 halite nodules collected in Salar Grande (Fig. 1) was

104 harvested using aseptic conditions in a laminar flow hood and pooled together for DNA

105 extraction, as previously described (Robinson et al., 2015). Sequencing was performed

106 on the Illumina HiSeq2500 at the University of Maryland School of Medicine Institute

107 for Genome Sciences (Baltimore, MD).

108 Whole Metagenome Analysis

109 Sequencing produced 95,230,365 paired-end reads. After quality control (see details in

110 supplementary material), reads were assigned taxonomy content using PhyloSift (Darling

111 et al., 2014) and the functional content was characterized using the analysis server MG-

112 RAST (Meyer et al., 2008). The metagenome was assembled using the IDBA-UD

113 assembler (Peng et al., 2012). We use a $k$ range of 20-100 with a pre-correction step

114 before assembly, producing a meta-assembly with a mean contig size of 1,060 bp, a max 
115 contig size of $377,822 \mathrm{bp}$, and a contig n50 of 1,558 bp. Assembled contigs were grouped

116 into potential draft genomes using tetranucleotide frequencies, abundance levels, and

117 single-copy gene analysis with MaxBin (Wu et al., 2014). Genomic bins were assigned

118 taxonomic ranks with PhyloSift and Kraken (Darling et al., 2014, Wood and Salzberg

119 2014).

120 Algae genome

121 Genomic bin 18 contained a high number of eukaryotic marker genes $(\sim 1 / 3$ of all marker

122 genes in the bin), all of which were identified to belong to a member of the eukaryotic

123 green algae using BLASTP against the non-redundant (nr) database at NCBI. Contigs

124 assembly and annotation are further described in supplementary material.

\section{Nanohaloarchaea genome}

126 Four of the largest assembled contigs were binned together with MaxBin (Wu et al.,

127 2014) and identified as the partial genome of a member of the Nanohaloarchaea.

128 Reassembly methods (see details in supplementary material) resulted in a single

129 assembled genomic contig. The completed assembly was uploaded to and annotated

130 using the RAST server (Aziz et al., 2008). A CRISPR/Cas system was annotated using

131 RAST and CRISPRFinder (Grissa et al., 2007). BLASTN was used to match CRISPR

132 spacers to the assembled metagenome content.

133 Phylogenetic positioning of the novel Candidatus Nanopetramus SG9 genome was

134 performed by extracting 12 ribosomal marker genes shared by archaeal genomes with

135 PhyloSift (Darling et al 2014), aligning with MUSCLE (Edgar, 2004), and building a

136 Maximum-Likelihood tree with FastTree (Price et al., 2010) using concatenated

137 conserved blocks from each alignment (Gblocks) (Castresana 2000). The $\mathrm{G}+\mathrm{C}$ content of 
138 the CRISPR/Cas system was calculated and compared to the average $\mathrm{G}+\mathrm{C}$ content for 10

$139 \mathrm{kbp}$ windows across the entire genome. The phylogenetic position of the CRISPR/Cas

140 system was determined by aligning Cas 1 proteins from key archaeal species using

141 MUSCLE and by building a Maximum-Likelihood tree using FastTree.

\section{Viral genomes}

143 VirSorter (Roux et al., 2015) was used to extract viral genomic content from the

144 assembled metagenome and viral contigs greater than $12 \mathrm{kbp}$ were annotated and

145 examined. All contigs greater than $5 \mathrm{kbp}$ were checked for evidence of circularity using a

146 custom Python script, CircMG (https://github.com/alexcritschristoph/CircMG). The

147 RAST annotation server failed to annotate the majority of proteins encoded on the viral

148 contigs. ORFs were predicted for each putative genome with Prodigal (Hyatt et al.,

149 2010). To compare relationships within the halite viral community, all predicted viral

150 proteins were compared against all others using BLASTP and an e-value cutoff of 0.001,

151 producing a protein-protein similarity network. This network was used to build a virus-

152 virus weighted undirected network, where the edge weight between two viruses was

153 determined by the sum of the amino acid percent identity of all protein-protein matches

154 between two viruses, divided by the total number of predicted genes in both viral

155 genomes.

156 Community finding was run on the virus-virus network using the Walktrap community

157 finding algorithm (Pons and Latapy. 2005). All network analyses were done in R using

158 the igraph package (Csardi and Nepusz, 2006). The largest clusters in the protein-protein

159 network (representing conserved proteins) were annotated using BLASTP to the $\mathrm{nr}$

160 protein database (Gish and States 1993) and HHPred (Söding et al., 2005). 


\section{Sequence data and availability}

162 All sequences were deposited at the National Center for Biotechnology Information

163 Sequence Read Archive under Bioproject PRJNA296403 and accession number

164 SRP064713. The MG-RAST report for the data is available under ID 4600831.3

165 (http://metagenomics.anl.gov/linkin.cgi?metagenome=4600831.3).

166 Completed assemblies, annotation, and phylogenetic trees are available at

167 http://figshare.com/s/02565916783811e58e4b06ec4bbcf141

\section{Results}

170 Halite metagenome taxonomic and functional analyses

171 We characterized at the molecular level the endolithic microbial community from halite

172 nodules from Salar Grande (Fig. 1). Due to the difficulty in harvesting enough DNA from

173 the colonization zone of a single halite nodule, the metagenome was obtained with DNA

174 extracted from 5 different nodules. The metagenome sequence of the halite community

175 was composed of $9.6 \mathrm{~Gb}$ of high quality, paired-end, metagenomic shotgun sequences.

176 Taxonomic assignments of the metagenomic reads performed with PhyloSift (Darling et

177 al. 2014) revealed a community dominated by Archaea (71\%) and also composed of

178 Bacteria (27\%) and Eukarya (1\%) (Fig. 2). Halobacteria represented the majority of the

179 Archaea (90\%) with a small representation of Nanohaloarchaea ( 2\%). Most bacteria

180 belonged to the Salinibacter genera (63\%) and cyanobacteria constituted $15 \%$ of the

181 bacteria. Reconstruction of $16 \mathrm{~S}$ rRNA gene sequences from the metagenomic dataset

182 with EMIRGE (Miller et al., 2011) provided full-length genes for all the major

183 taxonomic groups and was consistent with our previous work using 16S rRNA gene 
184 sequencing (Robinson et al., 2015) (Fig. S1).

185 The functional composition of the halite metagenome was analyzed with MG-RAST

186 (Meyer et al., 2008) using total sequence reads (Fig. S2). Of the genes involved in carbon

187 metabolism, only $8 \%$ were allocated to autotrophic $\mathrm{CO}_{2}$ fixation (Fig. S3a) and the

188 Calvin-Benson cycle (CB) was the only pathway for autotrophic $\mathrm{CO}_{2}$ fixation (Fig. 3b).

189 The majority of the assigned RubisCO type I genes ( $>91 \%)$ were attributed to members

190 of the Cyanobacteria (Fig. S4). We identified a small number of RubisCO type III genes

191 and those were all from members of the Halobacteriaceae. Other key enzymes of the CB

192 pathway, phosphoribulokinase and sedoheptulose-1,7-bisphosphatase, were also present

193 and more than $99 \%$ of those sequences belonged to Cyanobacteria. Pathways for $\mathrm{CO}_{2}$

194 concentration (carboxysomes) and phosphoglycolate detoxification (photorespiration)

195 were also present in the halite metagenome and were from Cyanobacteria (Fig. S3b).

196 With respect to photosynthesis, most of the genes for Photosystem I and II (PSI and PSII)

197 major proteins, and for light harvesting complexes, belonged to Cyanobacteria with only

198 a small fraction assigned to green algae (Fig. S5 and S6). For all photosystems, 24 to

$19926 \%$ of all sequences were not given a taxonomic rank and $3 \%$ of PSII sequences were

200 assigned to unclassified viruses (Fig. S5b). Phototrophy was also supported via light-

201 driven proton pumps that belong to a number of heterotrophs including Roseiflexus

202 species (proteorhodopsin), Salinibacter (xanthorhodopsin), and Halobacteriaceae

203 (bacteriorhodopsin) (Fig. S7). Surprisingly, no nitrogenase (nif) genes were detected (Fig.

204 S8).

205 Osmotic adaptation of the algae from the halite community 
206 We found 89 complete or partially complete genes identified as belonging to a eukaryotic

207 alga with an average coverage of $7.2 \mathrm{x}$ and a maximum contig length of $3.9 \mathrm{kbp}$. The

208 majority of these genes mapped closely to homologs in either Ostreococcus tauri or

209 Micromonas sp. RCC299. Known genes included heat shock protein 70, DNA mismatch

210 repair protein MSH4, and multiple RNA splicing factors. Eukaryotic translation initiation

211 factors, RNA polymerase subunits, and multiple enzymes and ribosomal proteins were

212 also identified (Table S2). Using concatenated sequences of chloroplast and

213 mitochondrial genes, we found that the alga clustered with other members of the

214 Chlorophyta (Fig. S9), grouping consistently with the Micromonas and Ostreococcus

215 species and thereby confirming our previous phylogenetic position (Robinson et al.,

216 2015).

217 To reveal potential adaptations to high salt, we compared the isoelectric point (pI) of the

218 halite alga predicted proteins with that of the translated proteomes for Micromonas sp.

219 RCC299, O. tauri, and the reported proteins for Dunaliella salina, all belonging to

220 halophilic algae (Fig. 3) (Paul et al., 2008). Proteins from the halite alga had a

221 statistically significantly lower mean pI (6.19) than the known reference proteins from

222 Micromonas sp. RCC299 (6.97), O. tauri (7.60), and D. salina (7.7) (Mann-Whitney t-

223 test; $\mathrm{p}<0.001)$. Isoelectric point distributions were compared using nonparametric

224 statistical tests. Using a paired one-sided Wilcoxon t-test, we found that the predicted

225 halite alga proteins had significantly lower pI when paired using BLASTP with O. tauri

226 homologues $(\mathrm{n}=85 ; \mathrm{p}<0.001$; difference of means: 0.55$)$ and with Micromonas sp.

227 RCC299 homologues $(n=87 ; p=0.025$; difference of means: 0.24$)$. A paired-sample

228 bayesian model comparison, implemented with BEST (Bååth, 2014, Kruschke, 2013), 
229 reported that the probability that the proteins of the halite alga had a lower mean $\mathrm{pI}$

230 (difference of means less than 0) than that of Micromonas sp. RCC299 was 97.9\%. This

231 analysis predicted that the halite alga might have one of the lowest protein pI

232 distributions of any reported eukaryote.

233 The halite metagenome also contained a number of genes from algal organelles. A 29.8

234 kbp contig with $39 \% \mathrm{G}+\mathrm{C}$ carried several chloroplast genes with high similarity to the $O$.

235 tauri chloroplast genome, which is $71.7 \mathrm{kbp}$ and $39.9 \% \mathrm{G}+\mathrm{C}$. Genes encoding for PSI

236 and PSII protein subunits, cytochrome protein subunits, ribosomal proteins, and for

237 rRNAs and tRNAs were also found on the $29.8 \mathrm{kbp}$ contig. In the same genomic bin, we

238 also found 8 non-overlapping contigs that contained mitochondrial genes from algae. The

239 combined non-overlapping contigs were $45.4 \mathrm{kbp}$ in length with $37.1 \% \mathrm{G}+\mathrm{C}$, similar to

240 the $44.2 \mathrm{kbp}$ mitochondrial genome of O. tauri $(38.2 \% \mathrm{G}+\mathrm{C})$. These genomic fragments

241 were found to be enriched in tRNAs and organelle genes. Predicted proteins for the

242 organelles had mean pI values above 8, which may indicate different environmental

243 conditions in the organelle than in the intracellular space (Table S2).

244 The complete genome sequence for a novel Nanohaloarchaea

245 Our genome assembly produced a nanohaloarchaeon genome of $1.1 \mathrm{Mbp}$ long, encoding

246 for 1,292 genes, and with a $\mathrm{G}+\mathrm{C}$ content of $46.4 \%$ (referred to as SG9) (Fig. 4). Although

247 read abundances show the assembled contigs represented only $\sim 1-3 \%$ of the population,

248 these contigs likely assembled well because of the small genome size (1.1 Mbp), low

249 levels of micro-diversity, and a genome coverage around 20. A phylogenetic analysis,

250 using a set of 12 conserved concatenated genes, showed that Candidatus Haloredivivus

251 (Ghai et al., 2011) was the closest known reference (Fig. 5). The 16S rRNA gene 
252 sequence of SG9 was 91\% identical to that of Candidatus Haloredivivus, and 90 and

$25388 \%$ identical to Candidatus Nanosalina and Candidatus Nanosalinarum, respectively,

254 and in agreement with our concatenated protein phylogeny. We have named this new

255 microorganism, SG9, as Candidatus Nanopetramus SG9 (petramus: rock).

256 The SG9 genome was highly reduced and mostly composed of protein encoding genes,

257 similar to previously reported genomes for Nanohaloarchaea (Narasingarao et al., 2012)

258 (Fig. 4). RAST annotation of the genome revealed that $79 \%$ of predicted proteins could

259 not be assigned to known function. We predict that SG9 has a photoheterotrophic life

260 style as indicated by the presence of genes for rhodopsin biosynthesis, archaeal genes for

261 carbohydrate metabolism and a phosphoenolpyruvate-dependent sugar

262 phosphotransferase system (PTS). The glucose-6-phosphate dehydrogenase gene,

263 essential to the Pentose-Phosphate pathway and reported in both Candidatus Nanosalina

264 and Candidatus Nanosalinarum, was absent (Narasingarao et al., 2012). The presence in

265 the SG9 genome of three potassium uptake systems, Trk, Ktr and HKT, which in bacteria

266 are key components of osmotic regulation and resistance to high salinity (Becker et al.,

267 2014), along with systems for K homeostasis, indicated a potential "salt-in" strategy for

268 survival under high salt. This was supported by a low median pI for all Candidatus

269 Nanopetramus SG9 predicted proteins (pI 4.7) and a pI distribution similar to that of

270 Haloarcula hispanica, a salt-in strategist (Fig. S10). Potential motility was indicated by

271 the presence of genes for archaeal flagellar proteins. Genes for bacterial-like and

272 archaeal-like nucleotide excision repair pathways were also encoded in the SG9 genome,

273 together with a photolyase gene, and several homologs for the radA recombinase gene. 
274 We also found genes for isoprenoid biosynthesis, a S-layer protein, and for DNA 275 polymerases PolI and PolII, all genes typically found in archaea.

276 A Type I CRISPR/Cas system composed of eight CRISPR-associated proteins and a 277 spacer/repeat region with 22 spacers was found in the SG9 genome (Fig. 6a). We found 278 no evidence of a CRISPR system, or individual Cas proteins, in all publicly available 279 nanohaloarchaea genomes using CRISPR-finder (Grissa et al., 2007) and by searching 280 for the Cas1 protein with a Cas1-HMM alignment using Hmmer3 (Wheeler and Eddy 281 2013). The $11 \mathrm{kbp}$ CRISPR region of SG9 had a significantly lower $\mathrm{G}+\mathrm{C}$ content of $28241.5 \%$ than the whole genome (Fig. 6c). The difference in $\mathrm{G}+\mathrm{C} \%$, along with the absence 283 of any CRISPR loci in the genomes of its nearest neighbors, would indicate that SG9 284 acquired its CRISPR system via horizontal gene transfer (HGT) (Ochman et al., 2005). 285 To further elucidate the origins of the CRISPR/Cas system in SG9, the cas1 gene product 286 was aligned with Cas1 proteins from diverse archaeal genomes (Fig. 6b). The resulting 287 phylogeny showed that the Cas 1 protein was rooted within the Euryarchaeota, making it 288 likely that the locus was acquired from Methanobacteria or Halobacteria rather than the 289 phylogenetically closer Nanoarchaeota. While Halobacteria genomes are characterized 290 by high $\mathrm{G}+\mathrm{C} \%$, the genomes of Methanobacteria, Nanoarchaeota, and that of the 291 putative nanohaloarchaeal viruses (see below) all have low $\mathrm{G}+\mathrm{C} \%$ similar to the CRISPR 292 locus of SG9.

293 A BLASTN analysis of all 22 spacers from the SG9 CRISPR array against the assembled 294 halite metagenome returned a single hit for spacer 22 to contig Ha1987, which was found 295 to be a partial viral genome. Spacer 22 was located adjacent to the Cas genes cluster 296 indicating that it was the most recently added spacer to the CRISPR array. 


\section{Halite community viral diversity}

298 Analysis of contigs reported by VirSorter (Roux et al., 2015) and of circular viral contigs

299 (CircMG) resulted in the identification of over 30 complete or near complete viral or

300 proviral genomes in the halite metagenome (Tables 1 and S1). These viruses are novel

301 with a majority of viral protein products that were either hypothetical or had no homologs

302 in the $\mathrm{nr}$ database. Complete genome sizes ranged from $12 \mathrm{kbp}$ to $70 \mathrm{kbp}$ (Table 1).

303 While members of the Halobacteriales were the predicted hosts for a majority of the

304 viruses, the Nanohaloarchaea were predicted as putative hosts for viral genomes Ha139

$305(\mathrm{G}+\mathrm{C} \%$, host genes) and $\mathrm{Ha} 1987(\mathrm{G}+\mathrm{C} \%$, spacer match), and the cyanobacterium

306 Halothece for viral genomes Ha238 (host genes, $\mathrm{G}+\mathrm{C} \%$ ) and $\mathrm{Ha} 322$ (host genes, $\mathrm{G}+\mathrm{C} \%$ ),

307 based on the evidence indicated.

308 A majority of the annotated viral genomes shared few to no genes with other genomes,

309 making a phylogenetic or tree-based analysis impractical. To elucidate relationships

310 among viruses and the structure of the viral diversity in the halite community, we used a

311 network-based approach in which genomes were linked in a weighted network by the

312 proportion and percent identity of predicted proteins they shared with every other genome

313 (Fig. 7). The Walktrap community finding algorithm was used to then classify viral

314 genomes into one of six communities (I-VI), and representative members of each cluster

315 were further annotated and curated (Table 1)

316 The protein similarity network used to build the network of viral relationships was

317 examined for large clusters, which represented highly conserved proteins in the viral

318 population. The eight largest clusters were extracted and annotated using both HHPred

319 and BLASTP (Gish and States 1993, Söding et al., 2005) (Figure 8). This analysis 
320 confirmed that a majority of the viruses, particularly those in community I, had a head-

321 tail structure. Distinct BLASTP hits to putative host transcriptional regulators were found

322 throughout all the viral genomes and they often contained an HNH endonuclease domain.

323 DNA polymerases were common in the larger genomes and DNA helicases were

324 abundant in community III genomes.

325 Among haloviruses, the largest linear genomes, Ha32 and Ha68 (community II), were 326 structurally similar to each other and shared several genes with HSTV-2, an icosahedrally

327 symmetric Myovirus with host Halorubrum (Table 1). Both contained genes for tail

328 assembly proteins, baseplate and portal proteins, and a prohead protease, all

329 characteristics of large head-tail viruses. The circular Ha38 (community I) genome shared

330 few proteins with Ha32/Ha68, and most of the predicted protein products had no

331 homologs to haloviruses in the nr protein database. Ha38 shared several core phage genes

332 with Myovirus HGTV-1, including a major capsid protein and a prohead protease (Table

333 1). The genome of Ha38 also encoded DNA repair proteins (Rad25 and Hef nuclease)

334 and a transcription initiation factor TFIIB similar to archaeal hosts. Other large, circular

335 community I viruses (Ha86, Ha92) were not clearly related to any known halovirus and

336 shared a small number of proteins with HGTV-1, HSTV-1, and HHTV-1, while the

337 majority of encoded proteins had no known homologs (Table 1). Ha92 encoded for

338 several haloarchaeal and bacterial transcriptional regulators. The Ha86 genome encoded

339 for an ArsR family transcriptional regulator of the putative archaeal host and a cas6 gene

340 from a haloarchaea. Integrase genes were not found in Ha32 and Ha68, but were found in

341 Ha216, Ha68, and Ha1987. 
342 Genome Ha687 and the community III-associated genome Ha929 shared several genes

343 for the structural proteins VP2 and VP4 with published Halorubrum pleomorphic viruses,

344 including HRPV-1, a ssDNA halovirus (Table 1) (Pietila et al., 2010). Both Ha966 and

345 Ha934 (community IV) shared a majority of their proteins with each other and few with

346 other identified viruses from the literature or this analysis. The two genomes were both

347 circular and approximately $12 \mathrm{kbp}$ in length. They had similar structure and gene

348 composition but surprisingly their $\mathrm{G}+\mathrm{C}$ content differed by $6.6 \%$ (Table 1). Annotated

349 proteins in their genomes included the plasmid partition protein ParB, Zn-finger domain

350 proteins, and DNA and RNA polymerase subunits.

351 Genomes Ha322, Ha238, Ha1987, and Ha139 uniquely had G+C content below 48\%,

352 while haloviruses typically have GC\% above 50\% (Table 1) (Klein et al., 2002, Oren,

353 2006, Pagaling et al., 2007, Pietila et al., 2013b, Pietila et al., 2013c, Sencilo et al., 2013,

354 Tang et al., 2002, Tang et al., 2004). Spacer 22 from the CRISPR-Cas array above had an

355 exact BLAST match to the linear and partially complete genome Ha1987, linking this

356 virus to a Nanohaloarchaeal host. In addition, several of Ha1987 viral genes had close

357 hypothetical homologs to the published Candidatus Haloredivivus sp. G17 genome (Ghai

358 et al., 2011). Ha139 was also putatively assigned to a Nanohaloarchaeal host because of

359 its low $\mathrm{G}+\mathrm{C} \%$, a shared hypothetical gene product with Candidatus Nanosalina, and

360 because large number of gene products shared with environmental Halophage eHP-23

361 and eHP-35 and two viral genomes previously assigned a Nanohaloarchaeal host (Garcia-

362 Heredia et al., 2012).

363 Both linear and incomplete genomes Ha322 and Ha238 had their closest BLASTP hits to

364 multiple Synechococcus phage and cyanophage proteins, and had homologs for multiple 
365 genes in several cyanobacteria. These findings suggest that they might be novel

366 cyanophages targeting the Halothece members of the community. Despite multiple close

367 BLASTP hits to cyanophage proteins in public datasets, Ha322 and Ha238 contigs shared

368 no homologous proteins with each other and did not cluster in the network analysis.

370 Discussion

371 Halite nodules in fossil continental evaporites from the Atacama Desert are at the 372 extreme of salt concentrations for hypersaline environments. Microorganisms inhabiting 373 this environment must balance the osmotic pressure of their cytoplasm with that of the 374 outside milieu. One osmotic strategy is the "salt in" strategy where ions, mainly $\mathrm{K}^{+}$and $375 \mathrm{Cl}^{-}$, are accumulated in the cell and the entire intracellular enzymatic machinery is 376 adapted to high salt (Oren, 2008). To remain soluble, the proteins of "salt-in" strategists

377 have an increased number of acidic amino acid residues on their surface, resulting in a 378 proteome with a low pI. This strategy is used by halophilic archaea and one extremely 379 halophilic bacterium, Salinibacter, a member of the Bacteroidetes (Oren, 2008). Other 380 halophilic and halotolerant microorganisms balance the high osmotic pressure of their 381 environment by synthesizing compatible solutes, a strategy called "salt-out" (Galinski, 382 1995, Oren, 2008).

383 Adaptation of the halite community to high salt

384 The phylogenetic composition of the halite community reflected the extreme salinity of 385 its environment with Archaea greatly outnumbering Bacteria (Ghai et al., 2011, Podell et 386 al., 2013, Robinson et al., 2015). In addition, most of the bacteria in the community 387 belonged to the genus Salinibacter, a "salt-in" strategist (Oren 2008). We found only one 
388 cyanobacteria, Halothece, as previously described using high-throughput 16S rRNA gene

389 sequencing (Robinson et al., 2015). Many species of cyanobacteria are adapted to high

390 salt and they often form dense benthic mats in saline and hypersaline environments,

391 where they are the main primary producers (Oren, 2015). However, above $25 \% \mathrm{NaCl}$

392 only cyanobacteria of the Aphanothecee-Halothece-Euhalothece cluster have been found

393 so far (de los Rios et al., 2010, Garcia-Pichel et al., 1998, Robinson et al., 2015,

394 Wierzchos et al., 2006). A property of this cluster is the production of abundant

395 extracellular polysaccharides (EPS) (de los Rios et al., 2010, Oren, 2015). We previously

396 reported that, in the halite nodules, Halothece formed cell aggregates surrounded by a

397 thick sheath embedded in EPS (de los Rios et al., 2010, Robinson et al., 2015). It is likely

398 that these structural components play a significant role in the desiccation tolerance of

399 Halothece and its ability for photosynthetic $\mathrm{O}_{2}$ evolution (Tamaru et al., 2005).

400 We found evidence of autotrophic $\mathrm{CO}_{2}$ fixation via the $\mathrm{CB}$ pathway by cyanobacteria in

401 the halite metagenome. Although we also found RubisCO type III gene in several archaea,

402 it is not clear whether this enzyme participate in autotrophic $\mathrm{CO}_{2}$ fixation or in a novel

403 AMP recycling pathway (Falb et al., 2008, Sato et al., 2007). Our findings indicate that

404 the unique cyanobacteria is likely responsible for most of the $\mathrm{CO}_{2}$ fixed in the halite

405 community. In addition, we recently reported in situ carbon fixation through oxygenic

406 photosynthesis in halite nodules supporting the idea that cyanobacteria are the major

407 primary producers in this ecosystem (Davila et al., 2015). A number of organisms

408 encoded light-driven proton pumps in their genomes, carrying out photoheterotrophy and

409 significantly increasing the energy budget from light. 
410 We assembled the partial genes of the alga previously detected in the halite community,

411 together with large regions of the genomes of its mitochondria and chloroplast. The pI of

412 the alga predicted proteins was one of the lowest $\mathrm{pI}$ reported for any eukaryote (Kiraga et

413 al., 2007). In addition, the bimodal distribution of the proteins pI was similar to that of

414 "salt-in" strategists, suggesting that lower eukaryotes might potentially use intracellular

415 salt as a mean to balance osmotic pressure in hypersaline environments.c

\section{A novel nanohaloarchaeal genome with a CRISPR array}

417 We report here the first nanohaloarchaeon genome assembled into a single scaffolded 418 contig from metagenome data of hypersaline environments (Ghai et al., 2011, Martinez-

419 Garcia et al., 2014, Narasingarao et al., 2012, Podell et al., 2013). The Candidatus

420 Nanopetramu SG9 genome of 1.1 Mb is very similar in size to that of previously reported

421 Nanohaloarchaea and its genomic $\mathrm{G}+\mathrm{C}$ content is intermediate in the reported range

422 (Ghai et al., 2011, Narasingarao et al., 2012, Podell et al., 2013). Evidence from its

423 genome support the idea that Candidatus Nanopetramus SG9 has a photoheterotrophic

424 life-style and that it uses the "salt-in" strategy to counterbalance the high salt of its

425 environment. A low proteome pI has also been reported for Candidatus Nanoredivirus,

426 suggesting that the "salt-in" strategy might be a ubiquitous feature of Nanohaloarchaea

427 (Ghai et al., 2011). A unique attribute of Candidatus Nanopetramus SG9 was the

428 presence of a CRISPR array on its genome, demonstrating that adaptive immunity against

429 viruses is also a feature of Nanohaloarchaeal genomes. This is the first report of

430 annotated CRISPR-associated features in a nanohaloarchaeal genome and documented

431 acquisitions of CRISPR/Cas systems via HGT in the Archaea (Godde and Bickerton, 
432 2006, Portillo and Gonzalez, 2009, Brodt et al., 2011) support our hypothesis that SG9

433 acquired its CRISPR system via HGT.

434 The viral component of the halite community

435 With up to $10^{10}$ virus-like particles per $\mathrm{ml}$, hypersaline systems harbor some of the 436 highest viral concentrations of any aquatic environments (Baxter et al., 2011, Boujelben

437 et al., 2012). In these extreme environments, with very few eukaryotes, haloviruses are

438 likely to play an important role in shaping community structure through predation. We

439 have assembled over 30 complete to near complete viral genomes from a metagenome

440 obtained from the cellular fraction of the halite samples, restricting access to viruses that

441 were either contained inside cells at the time of sampling or associated with particle

442 surfaces. Despite this limitation, we found great viral diversity in the halite community in

443 terms of genome structure, genome size, $\mathrm{G}+\mathrm{C} \%$, and gene composition. These viruses

444 were novel with a majority of the viral protein products having no characterized

445 homologs. The viral genomes were not integrated within their host genomes in the

446 metagenome assembly, suggesting that most of the viruses were lytic rather than

447 lysogenic, in contrast to viruses found in high temperature environments (Anderson et al., 448 2015).

449 Viruses infecting haloarchaea come in a variety of virion morphotypes, including spindle450 shaped, pleomorphic, icosahedral, and head-and-tail (Atanasova et al., 2012, Pietila et al., 451 2013a, Roine and Oksanen, 2011). To date, 43 haloarchaeal tailed viruses have been 452 reported (Atanasova et al., 2012, Kukkaro and Bamford, 2009, Sabet, 2012) and 17 453 completely sequenced genomes, comprised approximately $1.2 \mathrm{Mb}$ of sequence 454 information (Klein et al., 2002, Pagaling et al., 2007, Pietila et al., 2013b, Pietila et al., 
455 2013c, Sencilo et al., 2013, Tang et al., 2002, Tang et al., 2004). Our analysis confirmed

456 that the majority of the viruses we identified in the halite metagenome also had a head-

457 tail structure, as previously found in other hypersaline environments (Garcia-Heredia et

458 al., 2012). The viral genetic diversity uncovered here hints that a significant portion of

459 the diversity of both head-tail and other viruses in halophilic environments still remains

460 largely unexplored.

461 Our network-based approach allowed us to analyze viral relationships in the community

462 and identify core protein encoding genes with similarity to previously described

463 haloviruses and cyanophages (Klein et al., 2002, Oren, 2006, Pagaling et al., 2007,

464 Pietila et al., 2013b, Pietila et al., 2013c, Sencilo et al., 2013, Tang et al., 2002, Tang et

465 al., 2004). Haloviruses genomes have rather high $\mathrm{G}+\mathrm{C}$ content (above 50\% on average),

466 also characteristic of haloarchaea, and the halite viruses followed that trend. The

467 exceptions were putative cyanophages and Nanohaloarchaea viruses that exhibited a

468 lower $\mathrm{G}+\mathrm{C}$ content, consistent with previous findings (Emerson et al., 2012, Martinez-

469 Garcia et al., 2014, Podell et al., 2013).

470 A number of partial halovirus genomes have been obtained from metagenomes from

471 crystallizer ponds and the hypersaline Lake Tyrrell in Australia with potential hosts

472 including Haloquadratum walsbyi, Nanohaloarchaea, and the bacterium Salinibacter

473 (Emerson et al., 2012, Garcia-Heredia et al., 2012). Here we described new groups of

474 viruses that prey on members of the Halobacteriales, the cyanobacterium Halothece, and

475 on a newly described Nanohaloarchaeon, Candidatus Nanopetramus SG9. CRISPR

476 sequences found in the newly described SG9 genome where also present on a partial viral 
477 genome, providing a direct connection between virus and host. However, these

478 predictions remain to be tested (Martinez-Garcia et al., 2014).

479 Despite the extreme stress of the halite environment, this work demonstrates that this

480 endolithic community is exquisitely adapted to the challenges of its environment.

481 Metagenomic analysis revealed a relatively complex community with members from the

482 three domains of life. It also revealed trophic levels, from photosynthetic primary

483 producers to heterotrophs, viral predations, and specific physiological adaptations to the

484 high osmotic pressure of the halite milieu. Further understanding of the major taxonomic

485 groups and essential metabolic pathways underlying the functioning of this unique

486 community will require a combination of field-based measurements of metabolic activity

487 coupled with meta-transcriptomics, to capture gene expression levels for specific function

488 and taxonomic groups.

490 Acknowledgements

491 This work was funded by grant EXOB08-0033 from NASA and grant NSF-0918907

492 from the National Science foundation to JDR, by grant CGL2013-42509P from MINECO

493 (Spain) to JW and by grant NNX12AD61G from NASA to AD. We thank Octavio

494 Artieda for support in the field and Carmen Ascaso for valuable discussions.

495

496

\section{Conflicts of Interests}


498 The authors declare that there are no competing financial interests in relation to the work

499 described here.

500

\section{References}

502 Anderson RE, Sogin ML, Baross JA (2015). Biogeography and ecology of the rare and 503 abundant microbial lineages in deep-sea hydrothermal vents. FEMS Microbiol Ecol 504 91: 1-11.

505 Atanasova NS, Roine E, Oren A, Bamford DH, Oksanen HM (2012). Global network of $506 \quad$ specific virus-host interactions in hypersaline environments. Environ Microbiol 14: $507 \quad 426-440$.

508 Aziz RK, Bartels D, Best AA, DeJongh M, Disz T, Edwards RA et al. (2008). The RAST 509 Server: rapid annotations using subsystems technology. BMC Genomics 9: 75.

510 Bååth R (2014). Bayesian First Aid: A Package that Implements Bayesian Alternatives to 511 the Classical *. test Functions in R. UseR 2014; Los Angeles, USA.

512 Baxter BK, Mangalea MR, Willcox S, Sabet S, Nagoulat MN, Griffith JD (2011). 513 Haloviruses of Great Salt Lake: A Model for Understanding Viral Diversity In: 514 Ventosa A, Oren A, Ma Y (eds). Halophiles and Hypersaline Environments. $515 \quad$ Springer-Verlag: Berlin Heidelberg. pp 173-190.

516 Becker EA, Seitzer PM, Tritt A, Larsen D, Krusor M, Yao AI et al. (2014). 517 Phylogenetically driven sequencing of extremely halophilic archaea reveals 518 strategies for static and dynamic osmo-response. PLoS Genet 10: e1004784. 
519 Boujelben I, Yarza P, Almansa C, Villamor J, Maalej S, Anton J et al. (2012).

520 Virioplankton community structure in Tunisian solar salterns. Appl Environ $521 \quad$ Microbiol 78: 7429-7437.

522 Brodt A, Lurie-Weinberger MN, Gophna U (2011). CRISPR loci reveal networks of gene 523 exchange in archaea. Biol Direct 6: 65.

524 Castresana J (2000). Selection of conserved blocks from multiple alignments for their use 525 in phylogenetic analysis. Mol Biol Evol 17: 540-552.

526 Cereceda P, Larrain H, Osses P, Farías M, Egaña I (2008a). The spatial and temporal 527 variability of fog and its relation to fog oases in the Atacama Desert, Chile. $528 \quad$ Atmospheric Res 87: 312-323.

529 Cereceda P, Larrain H, Osses P, Farías M, Egaña I (2008b). The climate of the coast and 530 fog zone in the Tarapacá Region, Atacama Desert, Chile. Atmospheric Res 87: 301$531 \quad 311$.

532 Chan Y, Lacap DC, Lau MC, Ha KY, Warren-Rhodes KA, Cockell CS et al. (2012).

533 Hypolithic microbial communities: between a rock and a hard place. Environ $534 \quad$ Microbiol 14: 2272-2282.

535 Chan Y, Van Nostrand JD, Zhou J, Pointing SB, Farrell RL (2013). Functional ecology 536 of an Antarctic Dry Valley. Proc Natl Acad Sci U S A 110: 8990-8995.

537 Clarke JDA (2006). Antiquity of aridity in the Chilean Atacama Desert. Geomorphology $538 \quad$ 73: 101-114.

539 Crabtree J, Agrawal S, Mahurkar A, Myers GS, Rasko DA, White O (2014). Circleator: 540 flexible circular visualization of genome-associated data with BioPerl and SVG. 541 Bioinformatics 30: 3125-3127. 
542 Crits-Christoph A, Robinson CK, Barnum T, Fricke WF, Davila AF, Jedynak B et al.

543 (2013). Colonization patterns of soil microbial communities in the Atacama Desert.

$544 \quad$ Microbiome 1: 28.

545 Csardi G, Nepusz T (2006). The igraph software package for complex network research.

$546 \quad$ Inter J Complex Systems 1695 http://igraph.org.

547 Darling AE, Jospin G, Lowe E, Matsen FAt, Bik HM, Eisen JA (2014). PhyloSift:

$548 \quad$ phylogenetic analysis of genomes and metagenomes. Peer J 2: e243.

549 Davila AF, Gomez-Silva B, de los Rios A, Ascaso C, Olivares H, McKay CP et al.

550 (2008). Facilitation of endolithic microbial survival in the hyperarid core of the

551 Atacama Desert by mineral deliquescence. J Geophys Res 113: G01028, 552 doi:01010.01029/02007JG000561.

553 Davila AF, Hawes I, Garcia J, Gelsinger DR, DiRuggiero J, Ascaso C et al. (2015). In

554 situ metabolism in halite endolithic microbial communities of the hyperarid Atacama

555 Desert. Frontiers Microbiol http://dx.doi.org/10.3389/fmicb.2015.01035.

556 de los Rios A, Valea S, Ascaso C, Davila AF, Kastovsky J, McKay CP et al. (2010).

557 Comparative analysis of the microbial communities inhabiting halite evaporites of 558 the Atacama Desert. Int Microbiol 2: 79-89.

559 DiRuggiero J, Wierzchos J, Robinson CK, Souterre T, Ravel R, Artieda O et al. (2013).

560 Microbial Colonization of Chasmoendolithic Habitats in the Hyper-arid Zone of the $561 \quad$ Atacama Desert. Biogeosciences 10: 2439-2450.

562 Edgar RC (2004). MUSCLE: multiple sequence alignment with high accuracy and high 563 throughput. Nucleic Acids Res 32: 1792-1797 
564 Emerson JB, Thomas BC, Andrade K, Allen EE, Heidelberg KB, Banfield JF (2012).

565 Dynamic viral populations in hypersaline systems as revealed by metagenomic $566 \quad$ assembly. Appl Environ Microbiol 78: 6309-6320.

567 Falb M, Muller K, Konigsmaier L, Oberwinkler T, Horn P, von Gronau S et al. (2008).

$568 \quad$ Metabolism of halophilic archaea. Extremophiles 12: 177-196.

569 Friedmann EI (1982). Endolithic Microorganisms in the Antarctic Cold Desert. Science 215: $1045-1053$.

571 Galinski EA (1995). Osmoadaptation in bacteria. Adv Microb Physiol 37: 272-328.

572 Garcia-Heredia I, Martin-Cuadrado AB, Mojica FJ, Santos F, Mira A, Anton J et al. 573 (2012). Reconstructing viral genomes from the environment using fosmid clones: the $574 \quad$ case of haloviruses. PLoS One 7: e33802.

575 Garcia-Pichel F, Nubel U, Muyzer G (1998). The phylogeny of unicellular, extremely 576 halotolerant cyanobacteria. Arch Microbiol 169: 469-482.

577 Ghai R, Pasic L, Fernandez AB, Martin-Cuadrado AB, Mizuno CM, McMahon KD et al. 578 (2011). New abundant microbial groups in aquatic hypersaline environments. Sci $579 \quad$ Rep 1: 135.

580 Gish W, States DJ (1993). Identification of protein coding regions by database similarity $581 \quad$ search. Nature Genet 3: 266-272.

582 Godde JS, Bickerton A (2006). The repetitive DNA elements called CRISPRs and their $583 \quad$ associated genes: evidence of horizontal transfer among prokaryotes. J Mol Evol 62: $584 \quad 718-729$. 
585 Grissa I, Vergnaud G, Pourcel C (2007). The CRISPRdb database and tools to display

586 CRISPRs and to generate dictionaries of spacers and repeats. BMC Bioinformatics 8:

$587 \quad 172$.

588 Hyatt D, Chen GL, Locascio PF, Land ML, Larimer FW, Hauser LJ (2010). Prodigal:

589 prokaryotic gene recognition and translation initiation site identification. BMC

$590 \quad$ Bioinformatics 11: 119.

591 Kiraga J, Mackiewicz P, Mackiewicz D, Kowalczuk M, Biecek P, Polak N et al. (2007).

592 The relationships between the isoelectric point and: length of proteins, taxonomy and 593 ecology of organisms. BMC Genomics 8: 163.

594 Klein R, Baranyi U, Rossler N, Greineder B, Scholz H, Witte A (2002). Natrialba

595 magadii virus phiCh1: first complete nucleotide sequence and functional 596 organization of a virus infecting a haloalkaliphilic archaeon. Mol Microbiol 45: 851597863.

598 Kruschke JK (2013). Bayesian estimation supersedes the t test. J Exp Psych Gen 142: $599 \quad 573-603$.

600 Kukkaro P, Bamford DH (2009). Virus-host interactions in environments with a wide 601 range of ionic strengths. Environ Microbiol Rep 1: 71-77.

602 Martinez-Garcia M, Santos F, Moreno-Paz M, Parro V, Anton J (2014). Unveiling viral603 host interactions within the 'microbial dark matter'. Nat Commun 5: 4542.

604 Meyer F, Paarmann D, D'Souza M, Olson R, Glass EM, Kubal M et al. (2008). The 605 metagenomics RAST server - a public resource for the automatic phylogenetic and 606 functional analysis of metagenomes. BMC Bioinformatics 9: 386. 
607 Narasingarao P, Podell S, Ugalde JA, Brochier-Armanet C, Emerson JB, Brocks JJ et al.

608 (2012). De novo metagenomic assembly reveals abundant novel major lineage of

609 Archaea in hypersaline microbial communities. ISME J 6: 81-93.

610 Ochman H, Lerat E, Daubin V (2005). Examining bacterial species under the specter of 611 gene transfer and exchange. Proc Natl Acad Sci U S A 102: 6595-6599.

612 Oren A (2006). The order halobacteriales. In: Dworkin M, Falkow S, Rosenberg E, 613 Schleife RK-H, Stackebrandt E (eds). The Prokaryotes. Springer;: Singapore. pp $614 \quad 113-164$.

615 Oren A (2008). Microbial life at high salt concentrations: phylogenetic and metabolic 616 diversity. Saline Systems 4: doi:10.1186/1746-1448-1184-1182.

617 Oren A (2015). Cyanobacteria in hypersaline environments: biodiversity and 618 physiological properties. Biodivers Conserv 24: 781-798.

619 Pagaling E, Haigh RD, Grant WD, Cowan DA, Jones BE, Ma Y et al. (2007). Sequence 620 analysis of an Archaeal virus isolated from a hypersaline lake in Inner Mongolia, 621 China. BMC Genomics 8: 410.

622 Pandit AS, Joshi MN, Bhargava P, Shaikh I, Ayachit GN, Raj SR et al. (2015). A 623 snapshot of microbial communities from the Kutch: one of the largest salt deserts in 624 the World. Extremophiles 19: 973-987.

625 Paul S, Bag SK, Das S, Harvill ET, Dutta C (2008). Molecular signature of hypersaline 626 adaptation: insights from genome and proteome composition of halophilic 627 prokaryotes. Genome Biol 9: R70. 
628 Peng Y, Leung HC, Yiu SM, Chin FY (2012). IDBA-UD: a de novo assembler for 629 single-cell and metagenomic sequencing data with highly uneven depth. $630 \quad$ Bioinformatics 28: 1420-1428.

631 Pietila MK, Laurinavicius S, Sund J, Roine E, Bamford DH (2010). The single-stranded 632 DNA genome of novel archaeal virus halorubrum pleomorphic virus 1 is enclosed in 633 the envelope decorated with glycoprotein spikes. J Virol 84: 788-798.

634 Pietila MK, Atanasova NS, Oksanen HM, Bamford DH (2013a). Modified coat protein 635 forms the flexible spindle-shaped virion of haloarchaeal virus His1. Environ $636 \quad$ Microbiol 15: 1674-1686.

637 Pietila MK, Laurinmaki P, Russell DA, Ko CC, Jacobs-Sera D, Butcher SJ et al. (2013b). 638 Insights into head-tailed viruses infecting extremely halophilic archaea. J Virol 87: 3248-3260.

640 Pietila MK, Laurinmaki P, Russell DA, Ko CC, Jacobs-Sera D, Hendrix RW et al. 641 (2013c). Structure of the archaeal head-tailed virus HSTV-1 completes the HK97 642 fold story. Proc Natl Acad Sci U S A 110: 10604-10609.

643 Podell S, Ugalde JA, Narasingarao P, Banfield JF, Heidelberg KB, Allen EE (2013). 644 Assembly-driven community genomics of a hypersaline microbial ecosystem. PLoS $645 \quad$ One 8: e61692.

646 Pointing SB, Chan Y, Lacap DC, Lau MC, Jurgens JA, Farrell RL (2009). Highly 647 specialized microbial diversity in hyper-arid polar desert. Proc Natl Acad Sci U S A 648 106: $19964-19969$.

649 Pointing SB, Belnap J (2012). Microbial colonization and controls in dryland systems. $650 \quad$ Nat Rev Microbiol 10: 551-562. 
651 Pons P, Latapy M (2005). Computing communities in large networks using random walks

652 arXiv:physics/0512106 [physicssoc-ph].

653 Portillo MC, Gonzalez JM (2009). CRISPR elements in the Thermococcales: evidence

654 for associated horizontal gene transfer in Pyrococcus furiosus. J. Appl Genet 50:

$655 \quad 421-430$.

656 Price MN, Dehal PS, Arkin AP (2010). FastTree 2--approximately maximum-likelihood 657 trees for large alignments. PLoS One 5: e9490.

658 Robinson CK, Wierzchos J, Black C, Crits-Christoph A, Ma B, Ravel J et al. (2015).

659 Microbial diversity and the presence of algae in halite endolithic communities are 660 correlated to atmospheric moisture in the hyper-arid zone of the Atacama Desert. $661 \quad$ Environ Microbiol 17: 299-315.

662 Rodriguez-Valera F, Martin-Cuadrado AB, Rodriguez-Brito B, Pasic L, Thingstad TF, 663 Rohwer F et al. (2009). Explaining microbial population genomics through phage $664 \quad$ predation. Nat Rev Microbiol 7: 828-836.

665 Roine E, Oksanen HM (2011). Viruses from the hypersaline environments: current 666 research an future trends. In: Ventosa A, Oren A, Ma Y (eds). Halophiles and 667 Hypersaline Environments. Springer: Heidelberg. pp 153-172

668 Roux S, Enault F, Hurwitz BL, Sullivan MB (2015). VirSorter: mining viral signal from 669 microbial genomic data. Peer J 3: e985.

670 Sabet S (2012). Halophilic viruses. In: Vreeland R (ed). Advances in Understanding the 671 Biology of Halophilic Microorganisms. Springer: New York, NY. pp 81-116 
672 Santos F, Yarza P, Parro V, Meseguer I, Rossello-Mora R, Anton J (2012). Culture673 independent approaches for studying viruses from hypersaline environments. Appl $674 \quad$ Environ Microbiol 78: 1635-1643.

675 Sato T, Atomi H, Imanaka T (2007). Archaeal type III RuBisCOs function in a pathway 676 for AMP metabolism. Science 315: 1003-1006.

677 Sencilo A, Jacobs-Sera D, Russell DA, Ko CC, Bowman CA, Atanasova NS et al. (2013). 678 Snapshot of haloarchaeal tailed virus genomes. RNA Biol 10: 803-816.

679 Sencilo A, Roine E (2014). A Glimpse of the genomic diversity of haloarchaeal tailed $680 \quad$ viruses. Front Microbiol 5: 84.

681 Söding J, Biegert A, Lupas AN (2005). The HHpred interactive server for protein 682 homology detection and structure prediction. Nucl Acids Res 33: W244-W248; 683 doi:210.1093/nar/gki1040.

684 Tamaru Y, Takani Y, Yoshida T, Sakamoto T (2005). Crucial role of extracellular 685 polysaccharides in desiccation and freezing tolerance in the terrestrial 686 cyanobacterium Nostoc commune. Appl Environ Microbiol 71: 7327-7333.

687 Tang SL, Nuttall S, Ngui K, Fisher C, Lopez P, Dyall-Smith M (2002). HF2: a double688 stranded DNA tailed haloarchaeal virus with a mosaic genome. Mol Microbiol 44: $689 \quad 283-296$.

690 Tang SL, Nuttall S, Dyall-Smith M (2004). Haloviruses HF1 and HF2: evidence for a 691 recent and large recombination event. J Bacteriol 186: 2810-2817.

692 Walker JJ, Pace NR (2007). Endolithic microbial ecosystems. Annu Rev Microbiol 61: $693 \quad 331-347$. 
694 Wei STS, Fernandez-Martinez M, Chan Y, Van Nostrand JD, de los Rios-Murillo A,

695 Chiu JMY et al. (2015). Diverse metabolic and stress-tolerance pathways in

696 chasmoendolithic and soil communities of Miers Valley, McMurdo Dry Valleys, 697 Antarctica. Polar Biol 38: 433-443.

698 Wheeler TJ, Eddy SR (2013). nhmmer: DNA Homology Search With Profile HMMs.

699 Bioinformatics 28: 2487-2489.

700 Wierzchos J, Ascaso C, McKay CP (2006). Endolithic cyanobacteria in halite rocks from 701 the hyperarid core of the Atacama Desert. Astrobiology 6: 415-422.

702 Wierzchos J, Davila AD, Sánchez-Almazo IM, Hajnos M, Swieboda R, Ascaso C 703 (2012a). Novel water source for endolithic life in the hyperarid core of the Atacama 704 Desert. Biogeosci Discuss 9: 3071-3098.

705 Wierzchos J, de los Ríos A, Ascaso C (2012b). Microorganisms in desert rocks: the edge 706 of life on Earth. Inter Microbiol 15: 173-183.

707 Wood DE, Salzberg SL (2014). Kraken: ultrafast metagenomic sequence classification 708 using exact alignments. Genome Biol 15: R46.

709 Wu YW, Tang YH, Tringe SG, Simmons BA, Singer SW (2014). MaxBin: an automated 710 binning method to recover individual genomes from metagenomes using an 711 expectation-maximization algorithm. Microbiome 2: 26.

712 Ziolkowski LA, Wierzchos J, Davila AF, Slater GF (2013). Radiocarbon evidence of 713 active endolithic microbial communities in the hyper-arid core of the Atacama 714 Desert,. Astrobiology 13: 607-616. 


\section{$716 \quad$ Figure legends}

717 Figure 1: (a) Shaded relief digital map of the northern Atacama Desert, Chile, with the

718 Salar Grande sampling location (triangle); (b) Salar Grande halite nodule field; (c)

719 Section of a halite nodule with a back arrow indicating the green diffuse colonization

720 zone.

721

722 Figure 2: Taxonomic assignments of the halite metagenome sequence reads using 723 Phylosift and displayed with Krona.

725 Figure 3: Comparison of isoelectric point profiles of the predicted proteomes for the 726 halite alga (blue) and 3 closely related halophilic algae, Micromonas sp. RCC299 (red),

727 Ostreococcus tauri (purple), and Dunaliella salina (orange). All reported protein 728 sequences in the $\mathrm{nr}$ database were used for Micromonas sp. RCC299 and O. tauri.

729 Sequences from the UniProt Protein database were used for D. salina.

730

731 Figure 4: Circular representation of the SG9 genome using the Circleator tool (Crabtree

732 et al., 2014). The $\mathrm{G}+\mathrm{C} \%$ of a $10 \mathrm{kbp}$ window is displayed on the outermost circle $(\mathrm{G}+\mathrm{C}$

733 scale: 40 to $50 \%$ ). Following circles represent predicted genes on the forward strand and

734 reverse strands, respectively; genes related to potassium homeostasis and uptake are in

735 red, genes related to a heterotrophic lifestyle are in green, genes related to DNA repair

736 are in purple, and Cas genes are in orange. The position of the ribosomal rRNA genes is

737 indicated in grey. 
739 Figure 5: Phylogenetic position of the novel Candidatus Nanopetramus SG9 genome

740 within the Archaea. The tree was built with alignments of concatenated genes for $r p s B$,

741 rplA, IF-2, rpsI, S5, S7, rplF, rplE, rpsK, S8, L18P/L5E, and rplM. Euryarcheota are in

742 Red, the TACK phyla in purple, Nanoarchaeota in blue, and the Nanohaloarcheota in

743 green. Bacterial species were used as an outgroup. The scale bar represents $0.2 \%$

744 sequence divergence. Bootstrap values (1000 replicates) are shown at nodes.

745

746 Figure 6: (a) A diagram of the CRISPR/Cas system found in the Candidatus

747 Nanopetramus SG9 genome; (b) phylogenetic analysis of Cas1 gene products. Bootstrap

748 values (1000 replicates) are shown at nodes; and (c) $\mathrm{G}+\mathrm{C} \%$ of a $10 \mathrm{kbp}$ windows, with a

$7491 \mathrm{kbp}$ step size, across the SG9 genome with the CRISPR $10 \mathrm{kbp}$ region marked by a red

750 line.

751

752 Figure 7: Phage-phage similarity network visualizing relationships between viral

753 genomes. Edges are weighted based on the proportion and \% ID of shared genes between

754 two genomes. Viruses are colored according to network communities predicted by the

755 Walktrap community finding algorithm: (I), blue; (II) red; (III) yellow; (IV) green; (V)

756 pink; (VI) orange.

757

758 Figure 8: Protein-protein similarity networks of the largest clusters of viral proteins,

759 colored by the cluster assigned to the derivative virus genome of each protein. 
761 Table 1: Viral genome composition and structure diversity.

\begin{tabular}{|c|c|c|c|c|c|}
\hline Contig & g Size GC\% & $\begin{array}{l}\text { Genome } \\
\text { Structure }\end{array}$ & Putative Host & Features & Virus group \\
\hline $\begin{array}{l}32 * \\
\text { (II) }\end{array}$ & 70.051 .5 & Linear & Halobacteria & $\begin{array}{l}\text { DNA pol II, B, RNA } \\
\text { ligase, tail assembly, } \\
\text { baseplate J, major capside, } \\
\text { prohead protease, portal } \\
\text { protein. }\end{array}$ & $\begin{array}{l}\text { Myovirus (similar to } \\
\text { HSTV-2) }\end{array}$ \\
\hline $38 *(\mathrm{I})$ & 64.054 .9 & Circular & Halobacteria & $\begin{array}{l}\text { DNA primase/helicase, } \\
\text { HNH, tape measure, major } \\
\text { capsid, prohead protease, } \\
\text { phage head } \\
\text { morphogenesis, terminase, } \\
\text { DNA pol II. }\end{array}$ & $\begin{array}{l}\text { Myovirus (similar to } \\
\text { HGTV-1) }\end{array}$ \\
\hline $\begin{array}{l}68^{*} \\
\text { (II) }\end{array}$ & 52.750 .3 & Linear & Halobacteria & $\begin{array}{l}\text { Portal protein, tail } \\
\text { assembly baseplate } J \text {, } \\
\text { RNA ligase, prohead } \\
\text { protein, integrase, DNA } \\
\text { pol II small subunit. }\end{array}$ & $\begin{array}{l}\text { Myovirus (similar to } \\
\text { HSTV-2) }\end{array}$ \\
\hline $92 *(\mathrm{I})$ & 44.563 .9 & Circular & Halobacteria & $\begin{array}{l}\text { HNH, DNA/RNA } \\
\text { Helicase, PadR TR, } \\
\text { terminase, major capsid, } \\
\text { tape measure, Zn finger. }\end{array}$ & Myovirus-like \\
\hline $86(\mathrm{I})$ & 46.263 .8 & $\begin{array}{l}\text { Linear / } \\
\text { Incomplete }\end{array}$ & Halobacteria & $\begin{array}{l}\text { Cas6, SNase-like protein, } \\
\text { HNH, major capsid, tail } \\
\text { protein, baseplate } \\
\text { assembly J. }\end{array}$ & $\begin{array}{l}\text { Myovirus-like (shares } \\
2 \text { genes with HHTV- } \\
\text { 1) }\end{array}$ \\
\hline $\begin{array}{l}139 * \\
\text { (I) }\end{array}$ & 34.143 .3 & Circular & Nanohaloarchae & $\begin{array}{l}\text { capsid protein, phage } \\
\text { terminase, excinuclease, }\end{array}$ & $\begin{array}{l}\text { Similar to } \\
\text { Environmental } \\
\text { Halophage eHP-23 } \\
\text { and eHP-35 }\end{array}$ \\
\hline $216^{*}$ & 26.465 & Circular & Halobacteria & $\begin{array}{l}\text { Integrase, RNA pol sigma } \\
24 \text { subunit, resolvase. }\end{array}$ & $\begin{array}{l}\text { No head/tail, similar } \\
\text { to Halosimplex } \\
\text { carlsbadense provirus }\end{array}$ \\
\hline $238(\mathrm{I})$ & 24.047 .2 & $\begin{array}{l}\text { Linear / } \\
\text { Incomplete }\end{array}$ & Halothece & $\begin{array}{l}\text { DNA primase/helicase, } \\
\text { DNA pol I, tail fiber, tape } \\
\text { measure }\end{array}$ & $\begin{array}{l}\text { Cyanophage; shares } \\
\text { genes with } \\
\text { Synechococcus phage } \\
\text { S-CBS4 and } \\
\text { cyanophage PSS2 }\end{array}$ \\
\hline
\end{tabular}




\begin{tabular}{lllll}
\hline $257^{*} 23.363 .2$ & Circular & Halobacteria & Phage repressor, & No head/tail; shares \\
(V) & & & replication protein, & genes with \\
& & & ATPase. & Halorubrum phage \\
& & & GNf2
\end{tabular}

\begin{tabular}{|c|c|c|c|c|c|}
\hline $\begin{array}{l}322 \\
(\mathrm{VI})\end{array}$ & 21.045 .2 & $\begin{array}{l}\text { Linear / } \\
\text { Incomplete }\end{array}$ & Halothece & $\begin{array}{l}\text { Phage tail protein, phage } \\
\text { baseplate protein. }\end{array}$ & $\begin{array}{l}\text { Cyanophage; Shares } \\
\text { genes with } \\
\text { Synechococcus phage } \\
\text { S-ShM2 and } \\
\text { Prochlorococcus } \\
\text { phage P-RSM4 }\end{array}$ \\
\hline $\begin{array}{l}687^{*} \\
\text { (III) }\end{array}$ & 14.461 .4 & Circular & Halobacteria & $\begin{array}{l}\mathrm{VP} 2, \mathrm{VP} 4 \text {, replication } \\
\text { protein. }\end{array}$ & $\begin{array}{l}\text { Shares genes with } \\
\text { Halobacteria } \\
\text { pleomorphic viruses }\end{array}$ \\
\hline $929 *$ & 12.362 .5 & Circular & Halobacteria & $\begin{array}{l}\text { RNA polymerase sigma- } 24 \\
\text { subunit, integrase, PhiH1 } \\
\text { repressor, VP1. }\end{array}$ & $\begin{array}{l}\text { Shares genes with } \\
\text { Haloarcula hispanica } \\
\text { icosahedral virus and } \\
\text { Halorubrum } \\
\text { pleomorphic virus } 3\end{array}$ \\
\hline $\begin{array}{l}934 \\
(\mathrm{IV})^{*}\end{array}$ & 12.357 .6 & Circular & Halobacteria & $\begin{array}{l}\text { DNA pol subunits, ParB, } \\
\text { Zn-finger domain. }\end{array}$ & $\begin{array}{l}\text { Shares gene with } \\
\text { HSTV-1 (Podovirus) }\end{array}$ \\
\hline $\begin{array}{l}966^{*} \\
\text { (IV) }\end{array}$ & 12.063 .9 & Circular & Halobacteria & ParB, Zn-finger domain. & $\begin{array}{l}\text { Shares gene with } \\
\text { HSTV-1 (Podovirus) }\end{array}$ \\
\hline $\begin{array}{l}1987 \\
\text { (III) }\end{array}$ & $8.4 \quad 46.1$ & $\begin{array}{l}\text { Linear / } \\
\text { Incomplete }\end{array}$ & Nanohaloarch & $\begin{array}{l}\text { CRISPR spacer match, } \\
\text { Integrase, VP4 precursor, } \\
\text { CopG TF. }\end{array}$ & \\
\hline
\end{tabular}

763 *Annotation curated and submitted; community type in parenthesis 


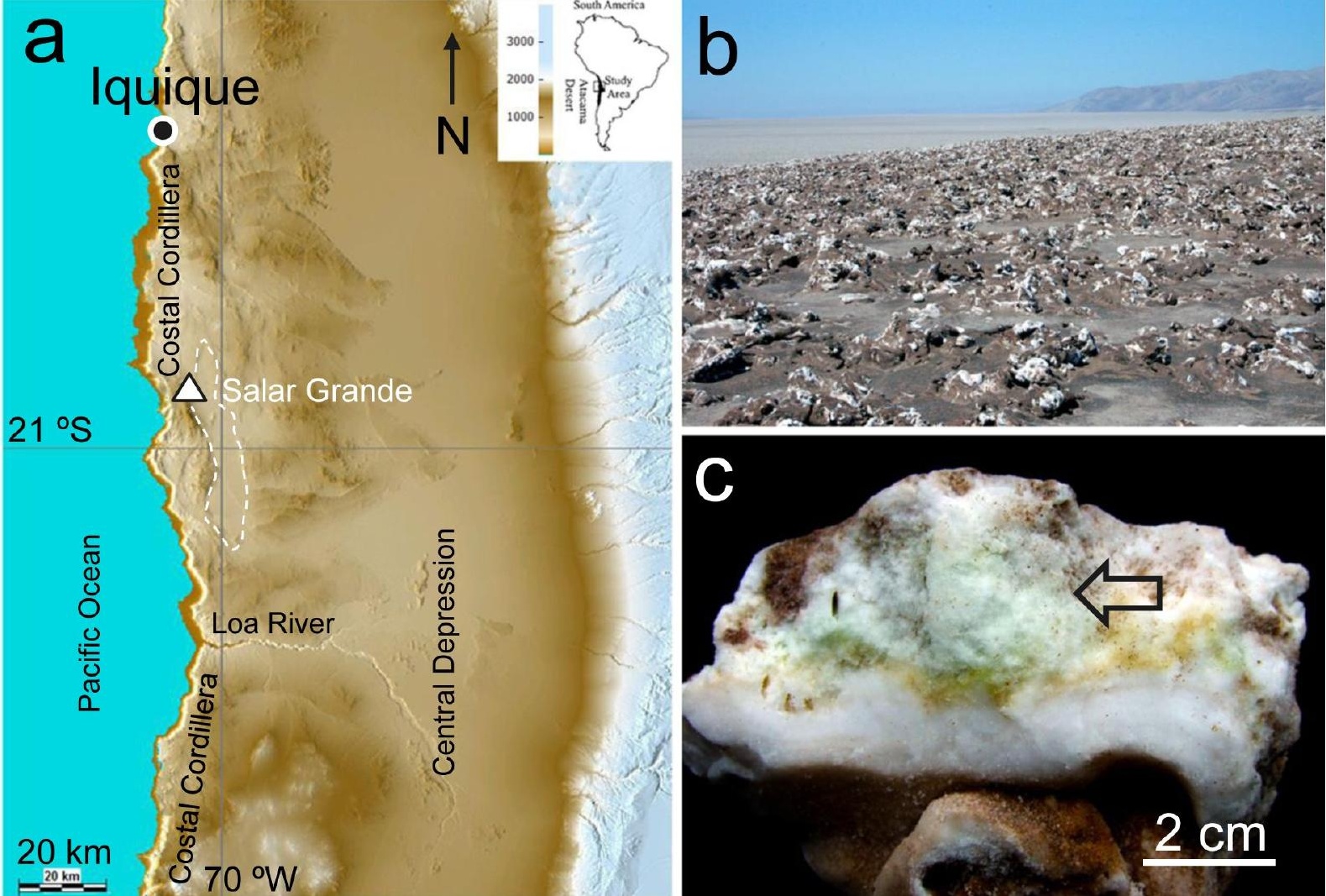




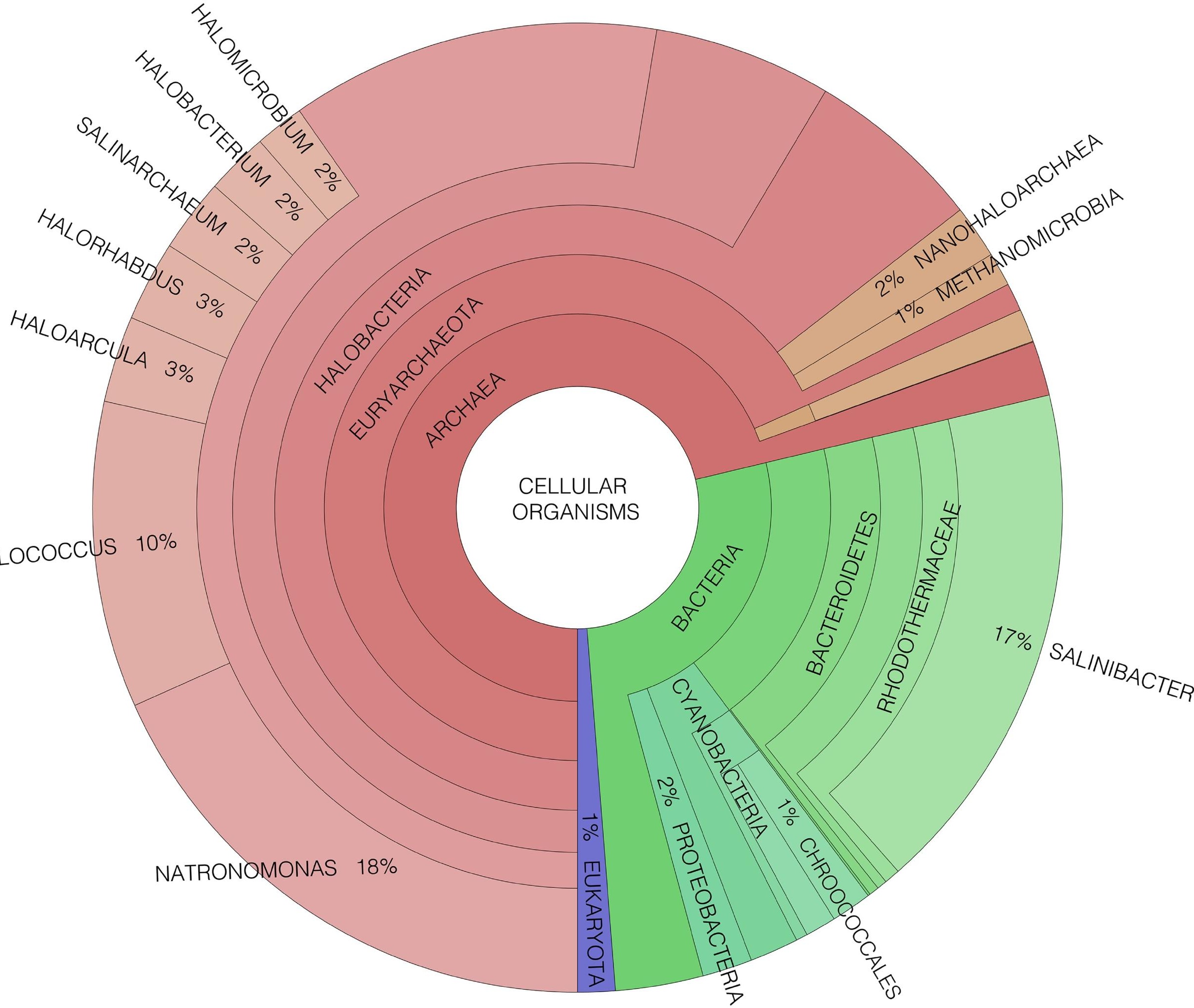




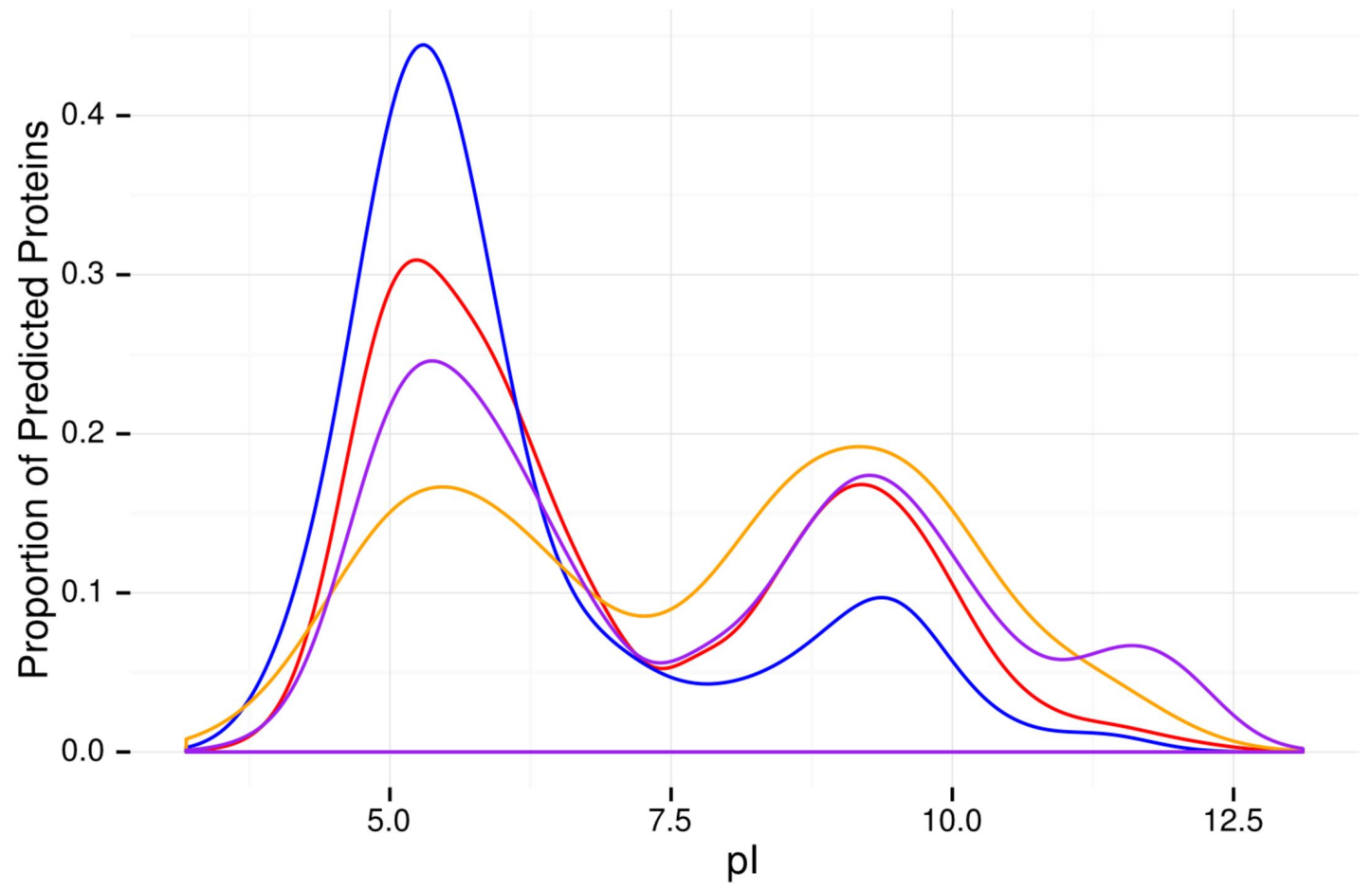




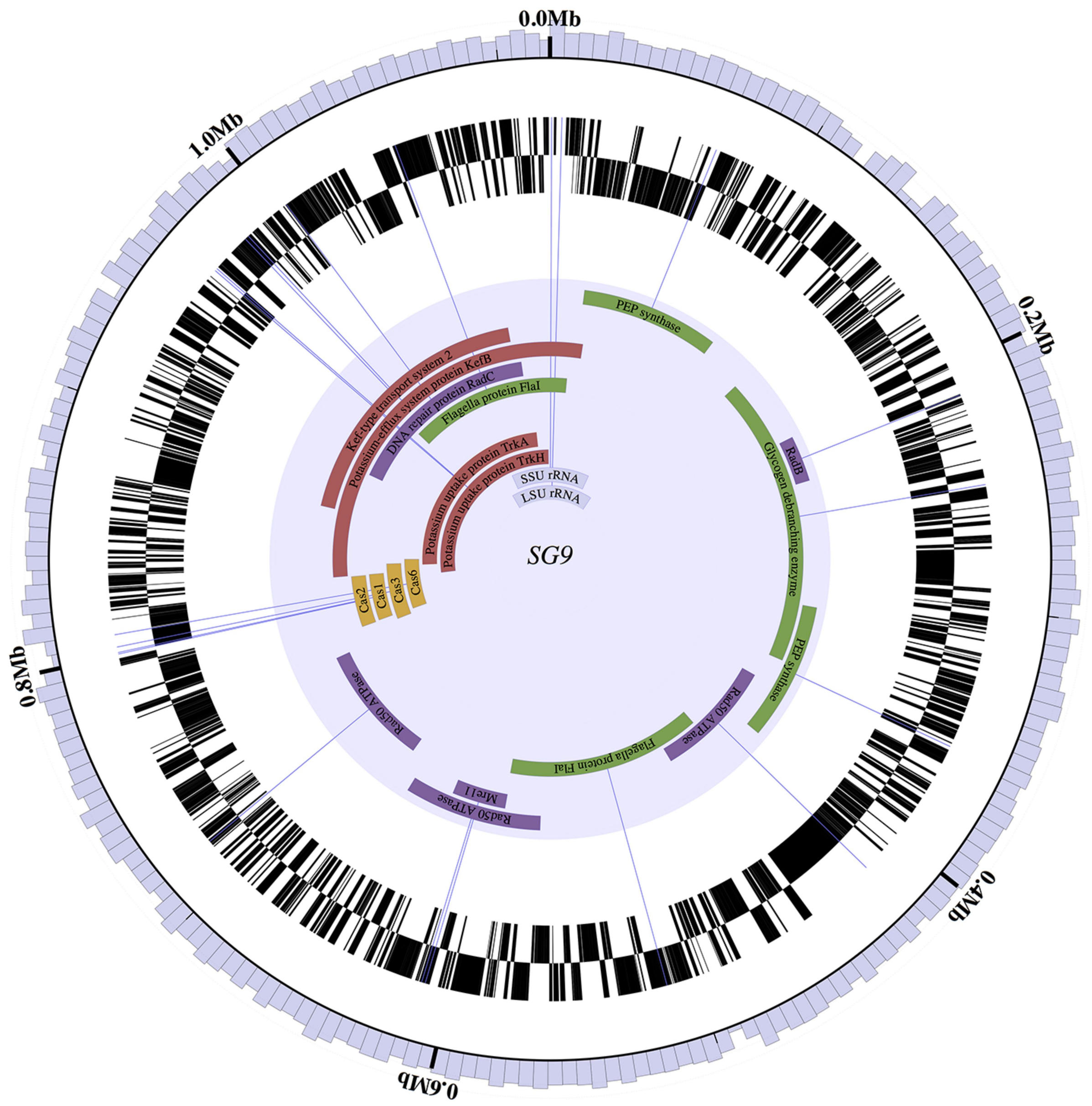


-Nanoarchaeum equitans

- Nanoarchaeota archaeon SCGC AAA011-L22

$\longrightarrow$ Aenigmarchaeota archaeon

-Candidatus Nanosalinarum sp. J07AB56

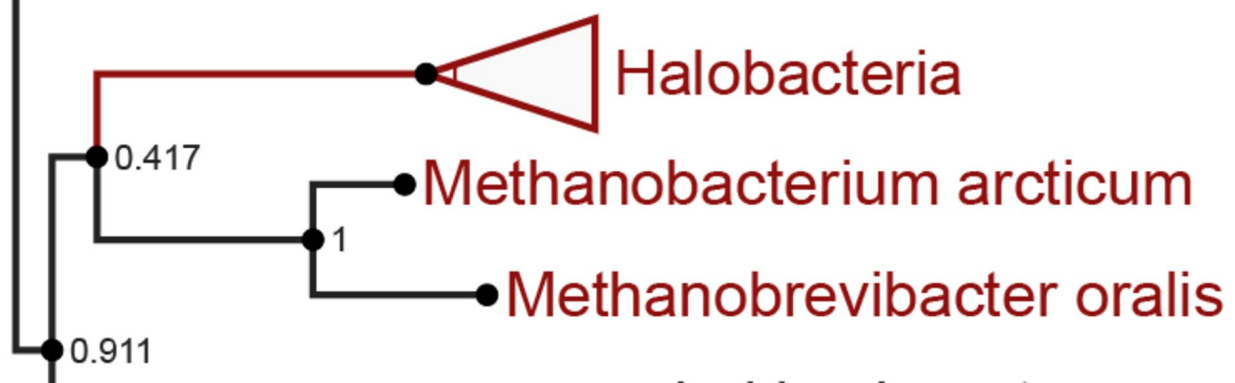

- Lokiarchaeota

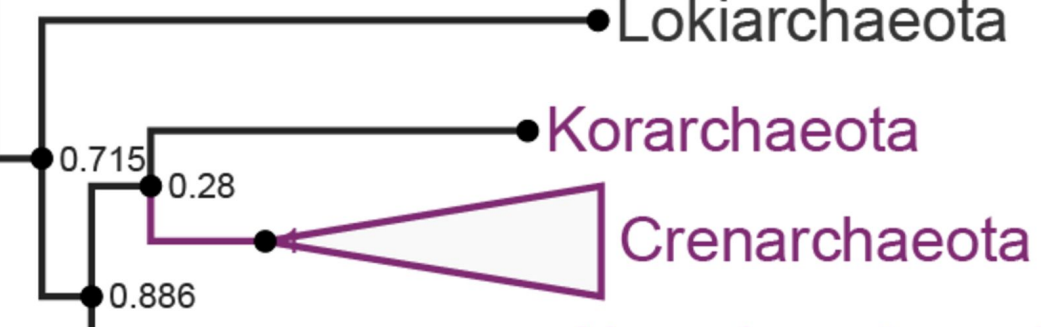

$\longrightarrow$ A Aigarchaeota archaeon (JGI)

-7 Thaumarchaeota

$\rightarrow$ Halothece sp. PCC 7418

-Salinibacter ruber M8 
a

\section{cas2 cas4a cas3}

\section{cas5h}

csh2

C

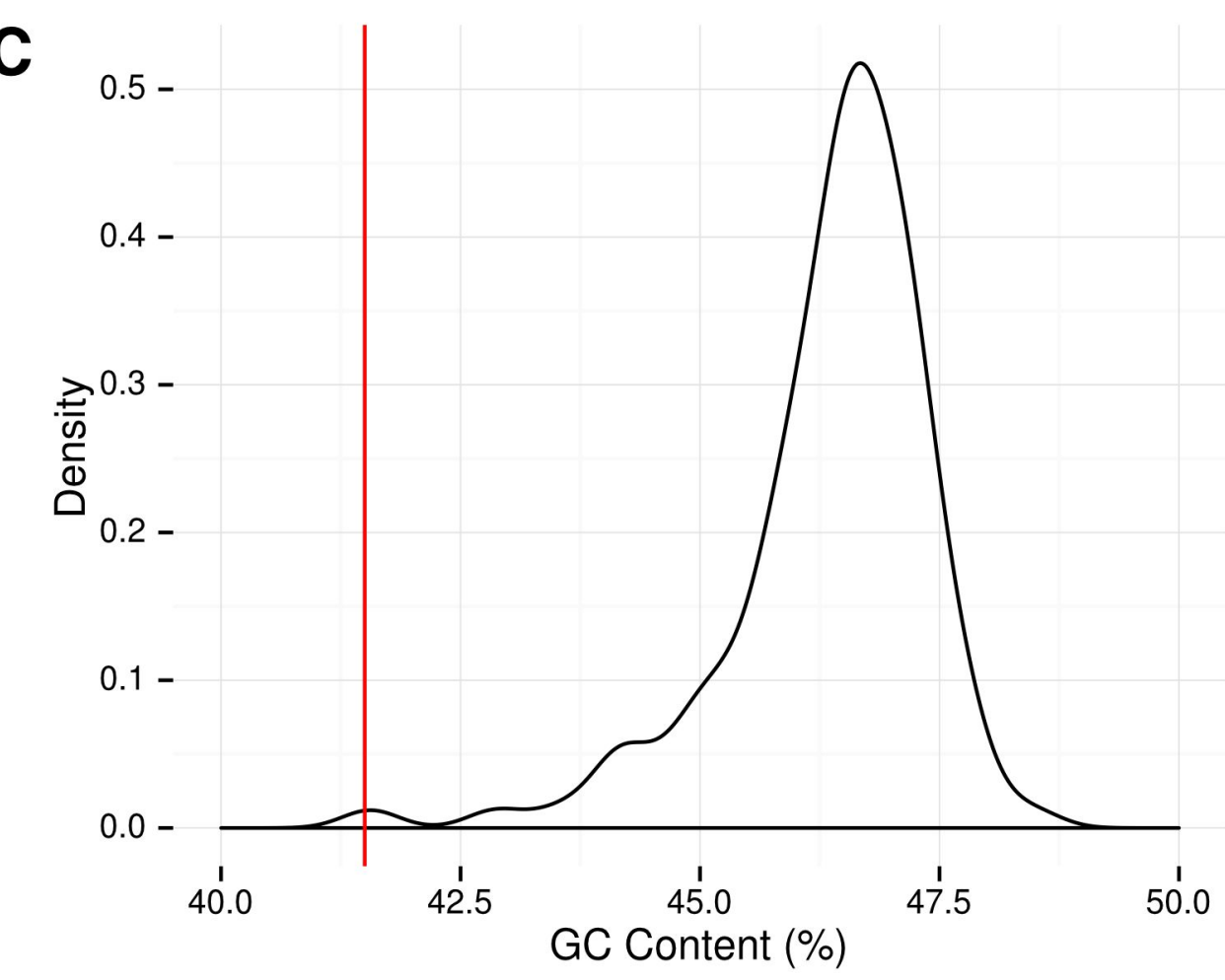

(hypothetical)

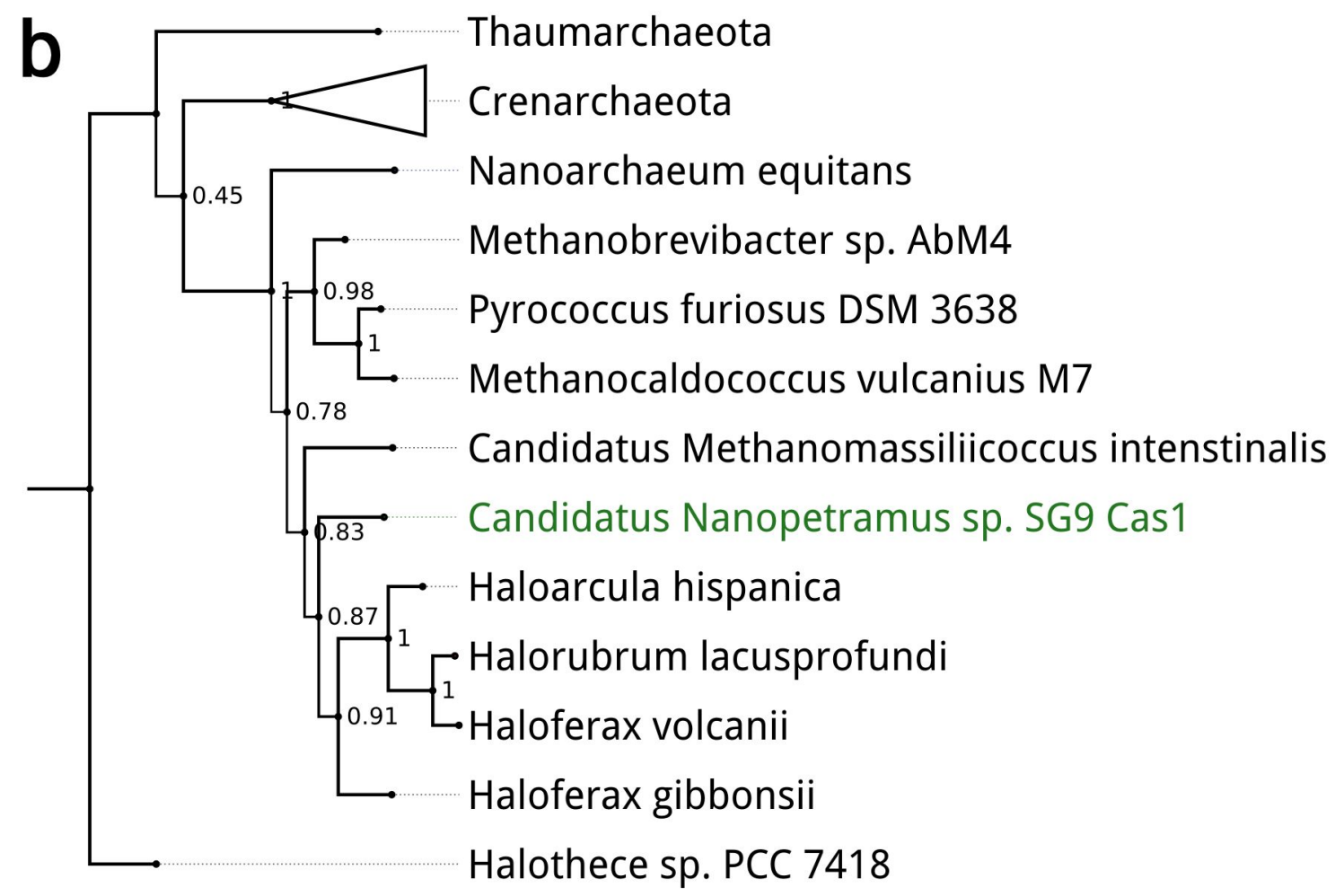




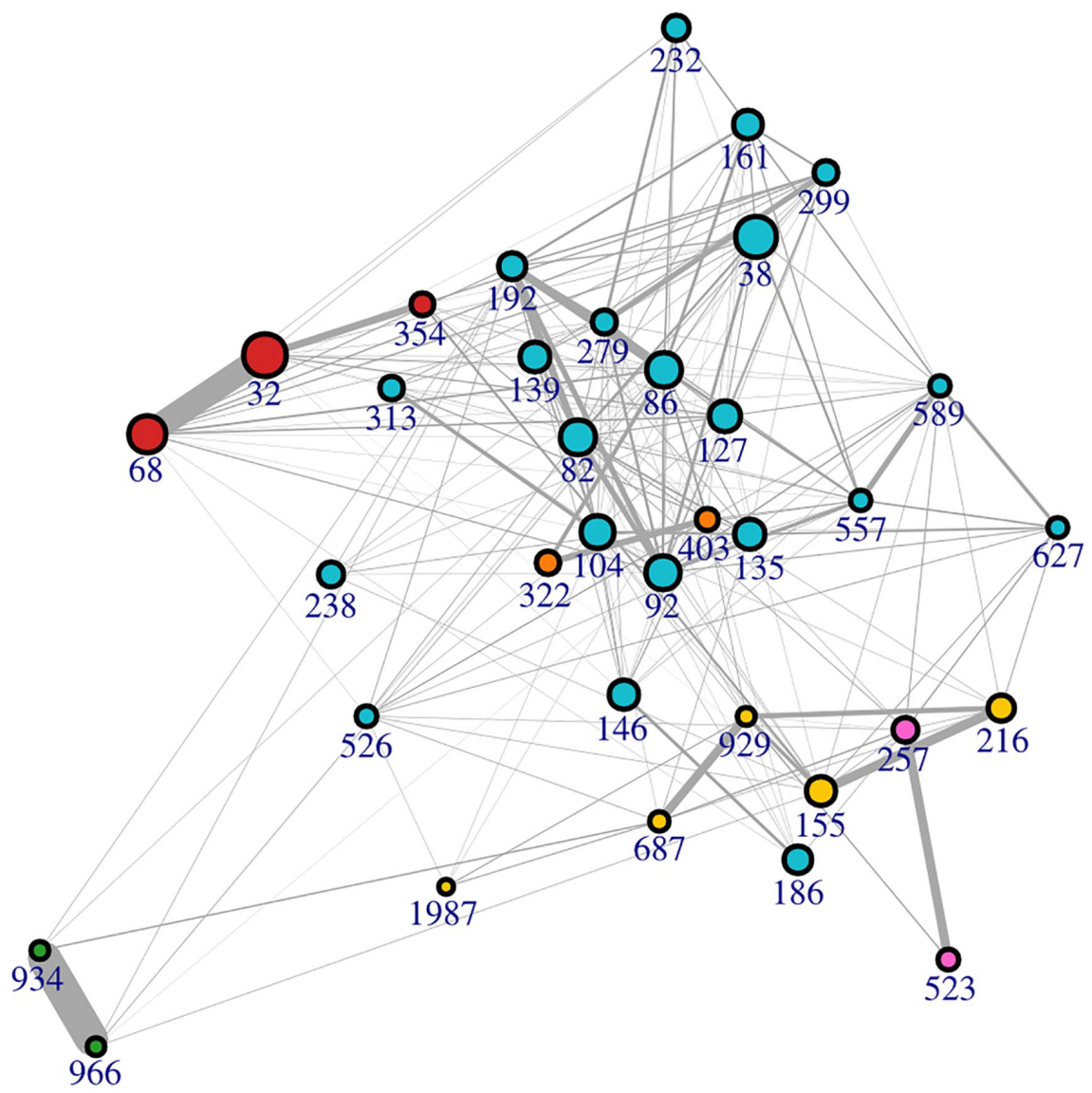


DNA polymerase $B$

Phage head assembly

DNA primase/helicase

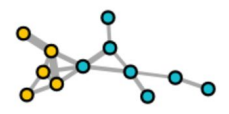

Terminase large subunit
$\mathrm{HNH}$ endonuclease associated

Tail tape measure

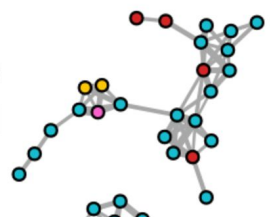

Terminase

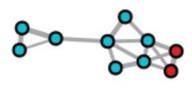

Prohead protease

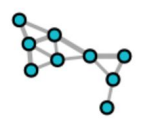

